\title{
Immediate and delayed memory tasks: A computerized behavioral measure of memory, attention, and impulsivity
}

\author{
DONALD M. DOUGHERTY, DAWN M. MARSH, and CHARLES W. MATHIAS \\ University of Texas Health Science Center, Houston, Texas
}

\begin{abstract}
The Immediate and Delayed Memory Task (IMT/DMT), a variant of the Continuous Performance Test (CPT), is a new software package designed to be a flexible research tool for the study of attention, memory, and impulsivity. This package allows researchers to determine the design to be used during a testing session and to manipulate many of the parameters. It features two components: the IMT and the DMT, both of which present sequential 2- to 7-digit stimuli with variable presentation rates and intertrial intervals. Subjects respond to identically matched stimuli presented consecutively, spanning a brief period of time (IMT), or to stimuli spanning a greater period of time (during which intervening stimuli to be ignored appear; DMT). Task complexity can be adjusted to suit applications for both children and adults. Preliminary studies have demonstrated that these laboratory tasks are sensitive to group differences, produce stable baselines of performance, and are sensitive to drug-induced performance decrements.
\end{abstract}

The Immediate and Delayed Memory Tasks (IMT/ DMT) were recently developed to accommodate the needs of researchers that were not being met by previous versions of the Continuous Performance Test (CPT; Cornblatt, Risch, Faris, Friedman, \& Erlenmeyer-Kimling, 1988; Rosvold, Mirsky, Sarason, Bransome, \& Beck, 1956). These previous versions were primarily developed for use with children or severely impaired populations and were most often used by clinics for diagnostic assessment. The IMT/DMT is a flexible research tool that was developed for the systematic study of sustained attention, working memory, and impulsivity in higher functioning populations. The program allows for the manipulation of a number of parameters to suit a particular research question or testing sample. This task was designed to measure brief attentional capacity in much the same manner as traditional CPTs, although the timing and complexity varies significantly from previous versions of the CPT. In addition, some of the response parameters appear to be sensitive to impulsive error responding (Dougherty, Bjork, Marsh, \& Moeller, 2000; Dougherty, Marsh, Moeller, Chokshi, \& Rosen, 2000; Dougherty et al., 1999).

Here, we will describe the IMT/DMT procedure, the parameters that can be manipulated by the experimenter, and the data that are collected and summarized. Some discussion will be provided regarding stability and sensitivity to independent variable manipulations.

This research was sponsored by Grant R01-MH63908 from the National Institute of Mental Health. Correspondence concerning this article should be addressed to D. M. Dougherty, Neurobehavioral Research Laboratory and Clinic, Department of Psychiatry \& Behavioral Sciences, University of Texas Health Science Center at Houston, 1300 Moursund Street, Houston, TX 77030 (e-mail: donald.m.dougherty@uth.tmc.edu).

\section{Task Overview and Descriptions}

This computer program has two major task components (see Figure 1): the IMT and the DMT. The software package (compatible with Windows 95, 98, and 2000) includes all necessary software on 3.5-in. floppy disks, standardized instructions with flash cards, and a detailed instruction manual. The program was written for presentation on any monitor, with the screen area set to $800 \times 600$ pixels. Other screen area sizes may be used, but stimulus size and screen placement may not be the same as described below.

Immediate Memory Task. In the IMT, a sequence of 2- to 7-digit numbers (e.g., 59213) appear on the computer monitor one-at-a-time for $500 \mathrm{msec}$ each, with a 500-msec intertrial interval (during which the computer monitor is completely white). The numbers are presented on the monitor in black on a white background, and each digit measures approximately $2.0 \mathrm{~cm}$ in width by $3.3 \mathrm{~cm}$ in height. During a standardized instruction procedure, participants are told to respond (i.e., click) using the left mouse button when the number that is currently displayed on the monitor is identical to the one that immediately preceded it.

Delayed Memory Task. In the DMT, subjects also match identical numbers, but the period of time separating the stimuli to be compared is longer, because a series of three distractor stimuli appear in between the two stimuli to be compared. For example, the distractor stimulus could be the number 12345, and a possible sequence involving matching stimuli could be $59213 \ldots 12345 \ldots 12345 \ldots 12345 \ldots$ 59213. Subjects are instructed to ignore the distractor presentations and to remember and compare the stimuli that are bounded by the series of distractor stimuli. These parameters not only increase the period of time required to remember and compare stimuli, but also control for the rate of visual stimulus presentation across the two tasks. 


\section{Immediate Memory Task}

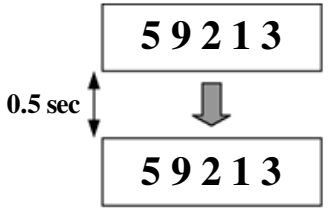

For both tasks, number stimuli are separated by an interstimulus interval that is adjustable ( $\geq 1 \mathrm{msec}$ ) to fit a variety of needs. This example shows a 0.5 -sec interval. In the IMT, participants respond to a number when it is identical to the preceding number. In the DMT, numbers to be compared are separated by $3.5 \mathrm{sec}$ and the distractor stimuli (12345 in this example) are ignored. There are four default presentation options plus a training session, but all options can be adjusted to suit individual requirements.

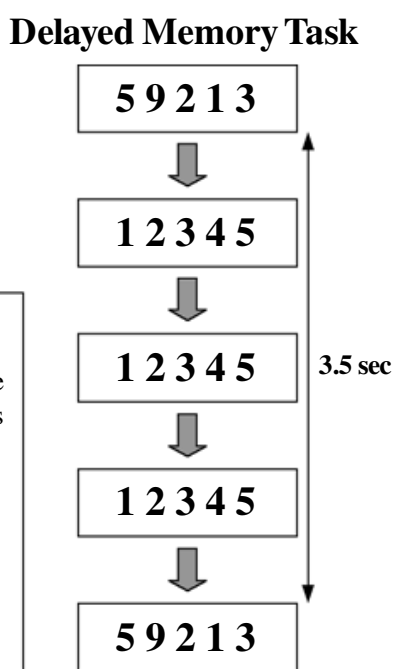

Figure 1. The primary distinction between the Immediate (IMT) and Delayed (DMT) Memory Task components. Both the IMT and the DMT present 2- to 7-digit stimuli. The IMT example (left) shows how 5-digit comparison stimuli are presented sequentially, separated by a 0.5 -sec interstimulus interval. The DMT example (right) shows how comparison stimuli are separated by three distractor stimuli (presented at the same 0.5 -sec interstimulus rate), which results in an overall 3.5 -sec separation of the comparison stimuli.
In the program's default mode (Immediate then Delayed Memory Task), the IMT and DMT components are each scheduled to last $5 \mathrm{~min}$ and are repeated in alternating blocks separated by a 30 -sec rest period. Thus, the default presentation sequence is IMT/DMT/IMT/DMT, and a complete testing session using the default condition lasts exactly $21.5 \mathrm{~min}$.

Stimulus types and recorded responses. There are three types of stimuli that can be generated during a testing session: target, catch, and filler stimuli.

Target stimuli are numbers presented that are identical to the numbers immediately preceding them. Responses to these stimuli are recorded as correct detections. These responses are thought to be related to attentional and memoryprocessing abilities (Barkley, 1991; Beale, Matthew, Oliver, \& Cornballis, 1987; Dougherty, Bjork, et al., 2000; Dougherty et al., 1999; Halperin, Wolf, Greenblatt, \& Young, 1991; Halperin et al., 1988; O’Toole, Abramowitz, Morris, \& Dulcan, 1997).

Catch stimuli are numbers presented that closely resemble the numbers immediately preceding them. Catch stimuli differ by only a single digit (e.g., 35027 followed by 35087); the position and value of the nonmatching digit is determined randomly. Responses to these stimuli are recorded as commission errors. Many researchers have interpreted elevated frequencies of commission errors as indicative of impulsive responding (Dougherty, Bjork, et al., 2000; Dougherty, Marsh, et al., 2000; Dougherty et al., 1999; Halperin et al., 1991; Halperin et al., 1988; O’Dougherty, Neuchterlein, \& Drew, 1984; Smith, Kendrick, \& Maben, 1992; Sostek, Buchsbaum, \& Rapoport, 1980;
Sykes, Douglas, \& Morgenstern, 1973; Sykes, Douglas, Weiss, \& Minde, 1971; Wohlberg \& Kornetsky, 1973).

Filler stimuli are numbers presented that are novel, differing from the numbers immediately preceding them (a random number generator produces these stimuli). Responses to these stimuli are recorded as filler errors. Subjects typically make few filler errors $(\leq 2.5 \%)$; therefore, elevated responses to filler stimuli usually indicate that the subject did not understand task instructions. A novel stimulus is always scheduled to occur after a target or catch stimulus appears, in order to avoid multiple matches' appearing in succession.

The rates, or probabilities, of occurrence for each of these three types of stimuli can be adjusted in a testing session (explained below). Under the program's default settings, the probabilities of target and catch stimuli are each set at $33 \%$ and the probability of filler stimuli is set at $34 \%$.

Response latencies to target (correct detections) and catch (commission errors) stimuli are recorded in milliseconds. Latency data are not collected for filler or distractor errors, because these errors are usually made so infrequently that statistical analyses would not be meaningful (Dougherty, Bjork, et al., 2000; Dougherty, Marsh, et al., 2000).

\section{Startup Menu and Program Settings}

After the program is initiated (IMTDMT_1.3.exe), a Startup Menu appears on the computer monitor identical to the one shown in Figure 2. This menu is used to set subject information and testing parameters for the testing session. Each section of this menu in Figure 2 is labeled with 


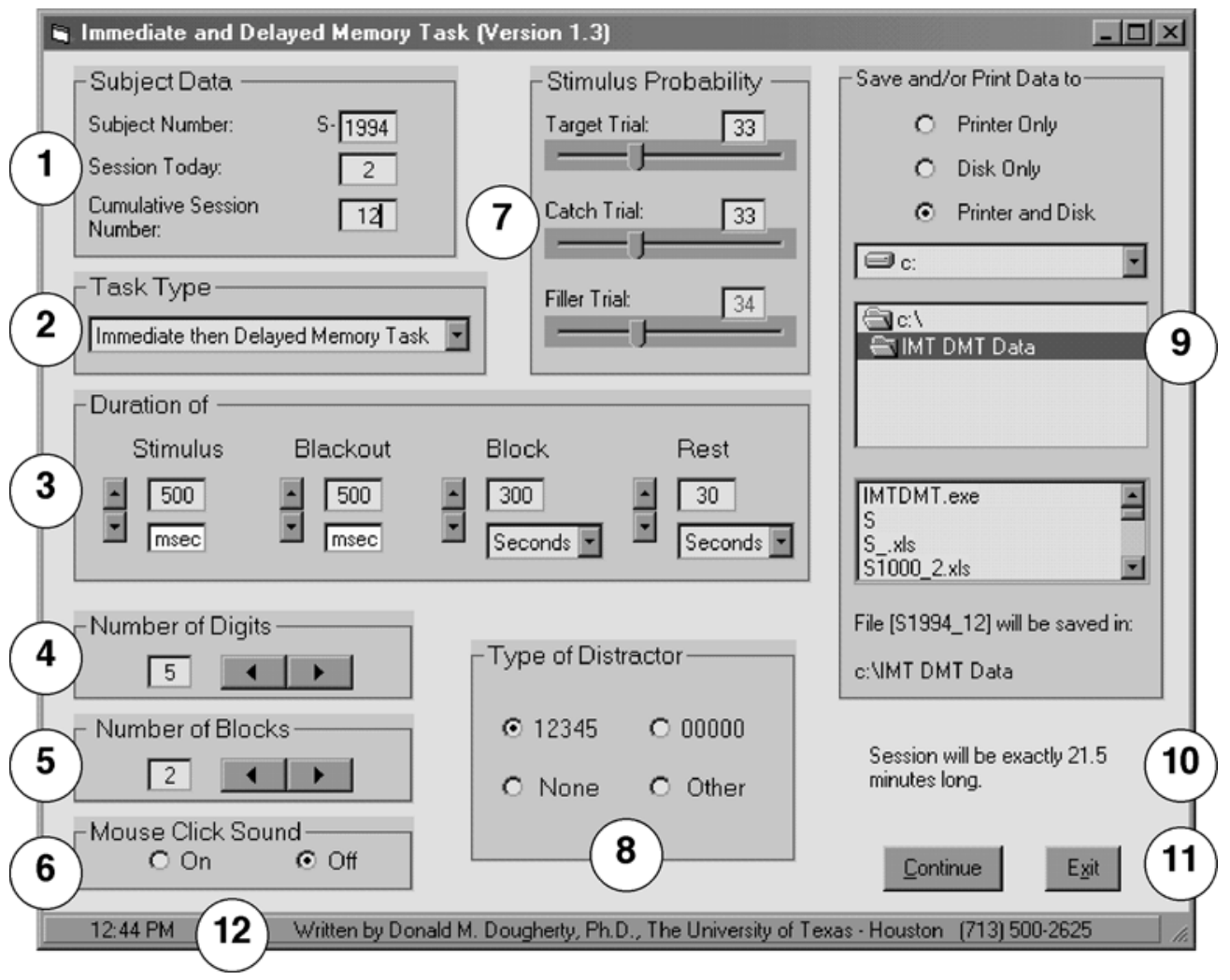

Figure 2. The IMT/DMT has a number of parameters that can be manipulated by the experimenter. This program Startup Menu depicts the areas used for adjusting the parameters of this versatile software package. These areas (numbered 1-12) are described in detail in the text.

a number, and the options and settings for each are briefly described below.

1. Subject Data. This is the area where subject identification data is entered (i.e., Subject Number, Session Number, and Cumulative Session Number). Identification data determine the name of the data file stored to disk at the session's completion.

2. Task Type. Five preset options can be accessed in the pull-down menu of this frame. Each of these options allows the experimenter to determine the tasks (IMT and/or DMT) to be used in a session, as well as their order of presentation (counterbalancing).

3. Duration of. Settings changed in this frame affect the rate of stimulus presentation and, consequently, session duration. Any changes to these settings automatically adjust the text appearing in the bottom right corner of the Startup Menu (No. 10 in Figure 2), indicating the session's duration. The following temporal parameters can be changed: Stimulus, Blackout, Block, and Rest.

4. Number of Digits. In this frame, the number of stimuli digits can be specified, ranging from 2 to 7 digits.

5. Number of Blocks. Number of Blocks controls the number of times each task is presented (range, 1-20 blocks).

6. Mouse Click Sound. This frame contains two option buttons (On or Off) that control the sound that the computer emits when the mouse button is depressed.
7. Stimulus Probability. The Stimulus Probability frame determines the probability of three different types of stimuli (target, catch, and filler) for any one trial.

8. Type of Distractor. This frame contains four options for selecting the type of distractor stimulus (see above) to be used in the DMT procedure: 12345,00000 , None, or Other. Selecting the Other option button produces a pop-up dialogue box prompting entry of any combination of characters or numbers to create a unique distractor stimulus.

9. Save and/or Print Data to. In this frame, the user determines where the session's data output will be sent, and the options are the following: Printer Only, Disk Only, or Printer and Disk. Data sent to the printer contain descriptive text and are structured in such a way that the data can be read easily. Data saved to disk contain only data (no descriptive text), which makes it easy to import into Microsoft Excel or statistical packages such as SPSS. An Excel template file with headings that identify each column of data is included with the IMT/DMT program package.

10. Session Length. In the lower right-hand corner of the Startup Menu is a text box that indicates session duration.

11. Continue/Exit Buttons. Two buttons, Exit and Continue, appear in the lower right-hand corner of the Startup Menu.

12. Status Bar. The time of day is listed on the status bar, and it is this time that is stored in the data output. 
Also, the contact information for the IMT/DMT developer is listed in the status bar.

\section{Beginning the Program}

Once the parameters of the Startup Menu have been set, pressing the Continue button will initiate the appearance of a screen with the words Ready to Begin (printed in black on a white background). This statement is presented in the middle of the screen just above a button labeled Press Return to Start that the subject can left-click on to start the program. The program can also be started by pressing the return/enter button or Alt $+\mathrm{r}$ on the keyboard.

\section{Recording Responses}

Subjects are instructed to use the mouse's left button. Other mouse button responses (e.g., from the right or center mouse buttons) are not recorded. Only one response in any trial is recorded. If the mouse is pressed more than once, the subsequent responses are not recorded. A response occurring less than $100 \mathrm{msec}$ after stimulus onset (i.e., presentation of a number) is not recorded, because it is likely to be the result of a slow response made to the previous stimulus (Halperin et al., 1988).

\section{Data Output}

An example of the IMT/DMT printer output appears in the Appendix (see also Save and/or Print Data, No. 9 above). Each of these sections (numbered on the sample data sheet in the Appendix) is described below.

1. Subject and Session Information. This first section lists the subject and session identification (entered in the Startup Menu) and the date and start time of the testing session (automatically acquired from the computer's calendar and clock).

2. IMT and DMT Data Sections. Directly below the subject and session information, the primary data are summarized for the following four categories: Block, Responses, Trials, and Percent.

3. Signal Detection Calculations. Both parametric $\left(d^{\prime}\right.$ is the measure of discriminability and beta indicates response bias; Gescheider, 1985; Green \& Swets, 1966) and nonparametric $\left(A^{\prime}\right.$ is the measure of discriminability and $B_{d}^{\prime \prime}$ indicates response bias; Donaldson, 1997) signal detection parameters are calculated for output.

4. Program Parameter Settings. Appearing at the bottom of the second page of the data printout is a summary of the program's settings used during the recorded testing session.

\section{Software Program Utility}

A number of studies have been completed recently that demonstrate the utility of the IMT/DMT in a wide range of applications in different populations. These studies fall into three categories: (1) studies comparing performance between groups, (2) studies investigating the effects of drugs and medications on performance, and (3) studies determining the relationship between biological measures and performance.

By using between-groups designs, normal controls have been compared with adolescents with disruptive behavior disorders (Dougherty et al., 2002; Mathias et al., 2002), adults with histories of conduct disorder/antisocial personality disorder (Dougherty, Bjork, et al., 2000), and hospitalized inpatients with schizophrenia (Dougherty et al.,
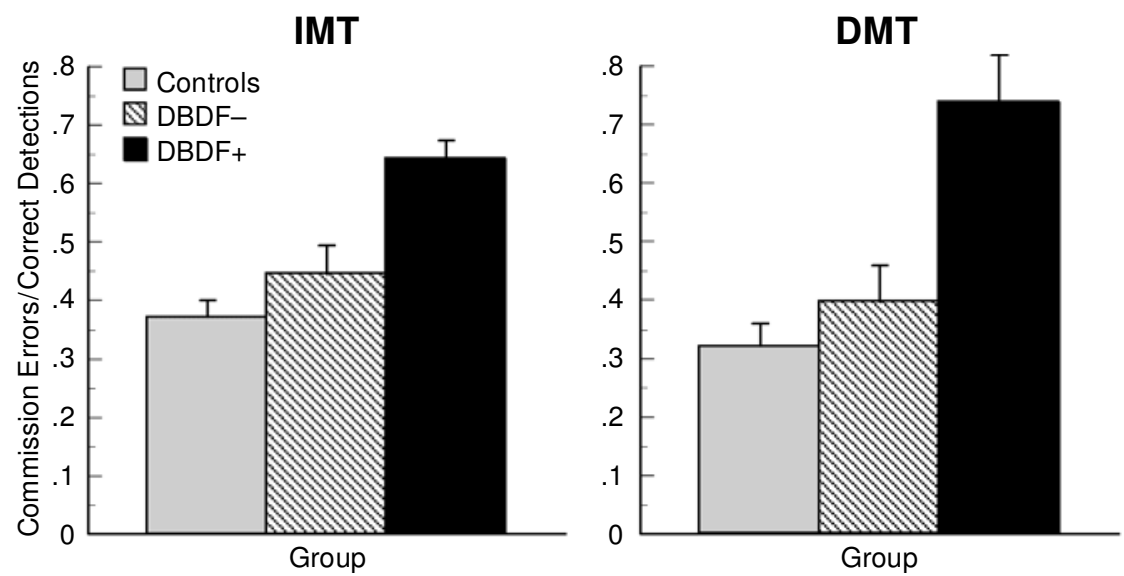

Figure 3. The sensitivity of the IMT/DMT for detecting subtle group differences. An adolescent control group was compared with two groups of adolescents with disruptive behavior disorders, one group with (DBDF + ) and one without (DBDF-) a history of initiating physical fights. The parameter in this illustration is the ratio of commission errors to correct detections, used as an indicator of impulsive-type responding. The orderly increase of these response rates matched the level of impaired impulse control of the three groups. Error bars represent SEMs. From Mathias et al. (2002). 
1998). Large performance differences have been observed between these populations, and frequently there are relationships between self-report measures of mood and behavior and IMT/DMT performance. For example, the results from a comparative study among adolescents differing in their histories of disruptive behavior disorders and physical fighting were clearly discriminated, using the proportion of commission errors relative to correct detections; these data appear in Figure 3.

The IMT/DMT is also sensitive to state-dependent changes produced by drug effects. For example, as compared with a placebo, alcohol decreases correct detections (Figure 4), increases the proportion of commission errors made relative to the number of correct detections, and can produce orderly changes in signal detection measures (Dougherty, Marsh, et al., 2000; Dougherty et al., 1999).

Preliminary studies in which the relationships between biological function and IMT/DMT performance have been investigated have indicated that plasma testosterone levels in women are positively correlated with commission error rates on the IMT/DMT (Bjork, Moeller, Dougherty, \& Swann, 2001). Genetic markers associated with the neurotransmitter serotonin have also been related to commission error performance (Bjork et al., 2002). Interestingly, we have also recently found that familial relationships (association between parents and adolescents) are relevant to performance on the IMT/DMT (Dougherty et al., in press).

The IMT/DMT has been shown to be a reliable measure within a session (across blocks), across multiple sessions conducted on the same day, and across days. A study of long-term reliability has been completed with a num- ber of subjects who were tested once per week across an 11-week period. This study clearly demonstrated both the reliability of repeated testing and the absence of practice effects as shown by the signal detection measure $A^{\prime}$ (Mathias, Marsh, \& Dougherty, in press). This stability is reflected in each of the primary variables of correct detections, commission errors, and the nonparametric signal detection measures of discriminability $\left(A^{\prime}\right)$ and response bias $\left(B_{d}^{\prime \prime}\right)$. Short-term reliability was demonstrated in a study of adults with conduct disorder (Dougherty, Bjork, et al., 2000) in which the subjects were tested across six sessions per day. Analyses showed no main effects between blocks within a session or between sessions in a day. Similar results have been obtained in studies of the effects of alcohol (Dougherty, Marsh, et al., 2000; Dougherty et al., 1999) on performance across days for baseline sessions, as well as across sessions and blocks during baseline and placebo testing days. The data from all these studies collectively illustrate the reliability of these measures.

\section{Conclusions}

In summary, these studies have demonstrated that the IMT/DMT (1) is sensitive to group differences, (2) is sensitive to the effect of alcohol, and (3) produces stable baselines of performance. Although much of our research has focused on the measurement of sustained attention (or vigilance), memory processing, and impulsive response characteristics in psychiatric populations, the IMT/DMT has been a useful tool well suited for the study of these basic mechanisms in normal populations (Dougherty et al., in press; Dougherty, Marsh, et al., 2000; Dougherty et al., 1999). Because the timing and stimulus complexity

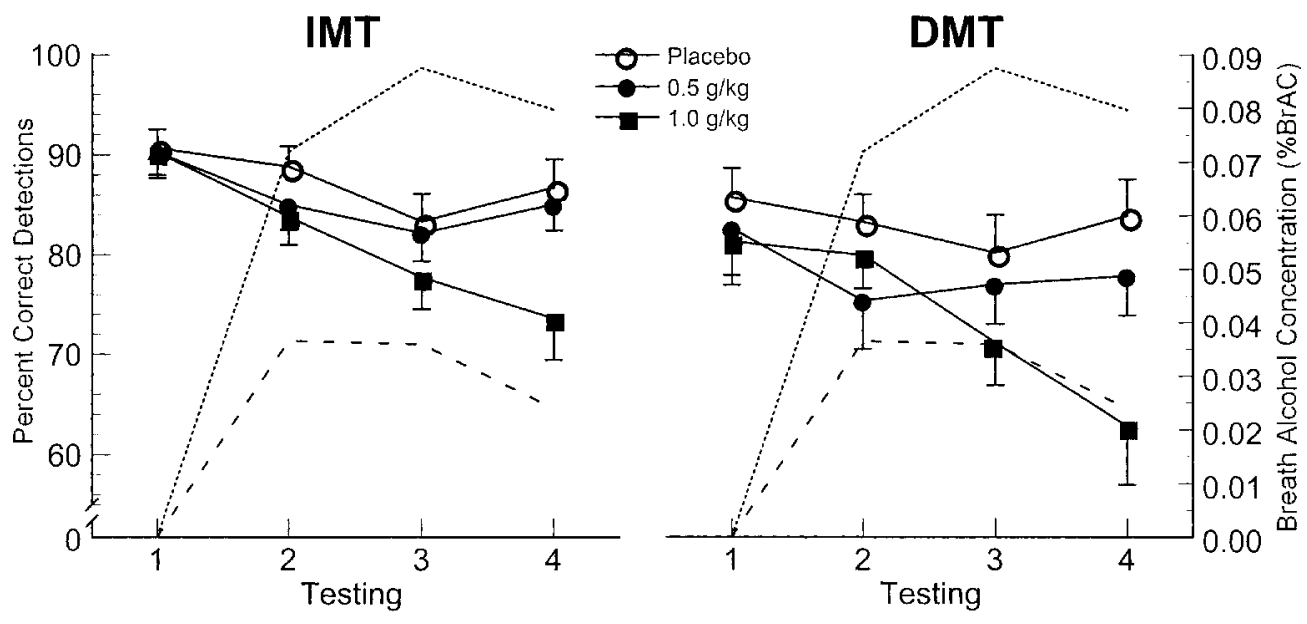

Figure 4. The IMT/DMT is also sensitive to state-dependent changes produced by drug effects. In this example, a group of normal controls experienced each of three conditions across 3 separate days: placebo, $0.5 \mathrm{~g} / \mathrm{kg}$ alcohol, and $1.0 \mathrm{~g} / \mathrm{kg}$ alcohol doses. Alcohol decreased correct detections relative to placebo, particularly for the $1.0-\mathrm{g} / \mathrm{kg}$ dose. The dashed and dotted lines represent the breath alcohol concentration curves for the $0.5-\mathrm{g} / \mathrm{kg}$ and $1.0-\mathrm{g} / \mathrm{kg}$ doses, respectively. Error bars represent $S E M \mathrm{~s}$. From "The Effects of Moderate and High Doses of Alcohol on Attention, Impulsivity, Discriminability, and Response Bias in Immediate and Delayed Memory Task Performance," by D. M. Dougherty, D. M. Marsh, F. G. Moeller, R. V. Chokshi, and V. C. Rosen, 2000, Alcoholism: Clinical \& Experimental Research, 24, p. 1705, Figure 2. Copyright 2000 by Lippincott, Williams, \& Wilkins. Reprinted with permission. 
of this task can be systematically manipulated, this program can be used in both normal and psychiatric populations ranging from children to adults.

\section{REFERENCES}

BARKLEY, R. A. (1991). The ecological validity of laboratory and analogue assessment methods of ADHD symptoms. Journal of Abnormal Child Psychology, 19, 149-178.

Beale, I. L., Matthew, P. J., Oliver, S., \& Cornballis, M. C. (1987). Performance of disabled and normal readers on the continuous performance test. Journal of Abnormal Child Psychology, 15, 229-238.

Buork, J. M., Moeller, F. G., Dougherty, D. M., \& Swann, A. C. (2001). Endogenous plasma testosterone levels and commission errors in women: A preliminary report. Physiology \& Behavior, 73, 217-221.

Bjork, J. M., Moeller, F. G., Swann, A. C., Dougherty, D. M., Machado, M. A., \& Hanis, C. L. (2002). Serotonin 2a receptor polymorphism and commission errors in a continuous performance test. American Journal of Medical Genetics, 114, 336-339.

Cornblatt, B. A., Risch, N. J., Faris, G., Friedman, D., \& ErlenmeyerKimling, L. (1988). The Continuous Performance Test, Identical Pairs Version (CPT-IP): I. New findings about sustained attention in normal families. Psychiatry Research, 26, 223-238.

DonAldson, W. (1997). Measuring recognition memory. Journal of Experimental Psychology: General, 121, 275-277.

Dougherty, D. M., Bjork, J. M., Harper, R. A., Mathias, C. W. Moeller,F. G., \& MARSH, D. M. (2002). Concurrent validation of the immediate and delayed memory tasks in hospitalized adolescents with disruptive behavior disorders. Manuscript submitted for publication.

Dougherty, D. M., Buork, J. M., Marsh, D. M., \& Moeller, F. G. (2000). A comparison between adults with conduct disorder and normal controls on a Continuous Performance Test: Differences in impulsive response characteristics. Psychological Record, 50, 203-219.

Dougherty, D. M., Bjork, J. M., Moeller, F. G., Harper, R. A., Marsh, D. M., Mathias, C. W., \& Swann, A. C. (in press). Familial transmission of ContinuousPerformance Test behavior: Attentional and impulsive response characteristics. Journal of General Psychology.

Dougherty, D. M., Marsh, D. M., Moeller,F. G., Chokshi, R. V., \& Rosen, V. C. (2000). The effects of moderate and high doses of alcohol on attention, impulsivity, discriminability, and response bias in immediate and delayed memory task performance. Alcoholism: Clinical \& Experimental Research, 24, 1702-1711.

Dougherty, D. M., Moeller, F. G., Steinberg, J. L., Marsh, D. M., Hines, S. E., \& BJorK, J. M. (1999). Alcohol increases commission error rates for a Continuous Performance Test. Alcoholism: Clinical \& Experimental Research, 23, 1342-1351.

Dougherty, D. M., Steinberg, J., Wassef, A. A., Medearis, D.,
Cherek, D. R., \& Moeller, F. G. (1998). Immediate versus delayed visual memory task performance among schizophrenic patients and normal controls. Psychiatry Research, 79, 255-265.

GescheIder, G. A. (1985). Psychophysics: Method, theory, \& application. Hillsdale, NJ: Erlbaum.

Green D. M., \& Swets J. A. (1966). Signal detection theory and psychophysics. New York: Wiley.

Halperin, J. M., Wolf, L., Greenblatt, E. R., \& Young, G. (1991) Subtype analysis of commission errors on the continuous performance test in children. Developmental Neuropsychology, 7, 207-217.

Halperin, J. M., Wolf, L. E., Pascualvaca, D. M., Newcorn, J. H., Healey, J. M., O’Brien, J. D., Morganstein, A., \& Young, J. G. (1988). Differential assessment of attention and impulsivity in children. Journal of American Child \& Adolescent Psychiatry, 27, 326-329. Mathias, C. W., Dougherty, D. M., Bjork, J. M., Harper, R. A., Moeller, F. G., \& Marsh, D. M. (2002, June). Continuous Performance Test: Adolescent performance differences are related to histories of physical fighting. Poster presented at the 14th Annual Meeting of the American Psychological Society, New Orleans.

Mathias, C. W., Marsh, D. M., \& Dougherty, D. M. (in press). Reliability estimates for the immediate and delayed memory tasks. Perceptual \& Motor Skills.

O’Dougherty, M., Neuchterlein, K. H., \& Drew, B. (1984). Hyperactive and hypoxic children: Signal detection, sustained attention, and behavior. Journal of Abnormal Psychology, 93, 178-191.

O'Toole, K., Abramowitz, A., Morris, R., \& Dulcan, M. (1997). Effects of methylphenidate and nonverbal learning in children with attention-deficit hyperactivity disorder. Journal of the American Academy of Child \& Adolescent Psychiatry, 36, 531-538.

Rosvold, H. E., Mirsky, A., Sarason, I., Bransome, E. D., Jr., \& BECK, L. H. (1956). A continuous performance test of brain damage. Journal of Consulting Psychology, 20, 343-350.

Smith, A., Kendrick, A., \& Maben, A. (1992). Use and effects of food and drinks in relation to daily rhythms of mood and cognitive performance: Effects of caffeine, lunch and alcohol on human performance, mood and cardiovascular function. Proceedings of the Nutrition Society, 51, 325-333.

Sostek, A. J., BuchsBaum, M. S., \& RAPOPORT, J. L. (1980). Effects of amphetamine on vigilance performance in normal and hyperactive children. Journal of Abnormal Child Psychology, 8, 491-500.

Sykes, D. H., Douglas, V. I., \& Morgenstern, G. (1973). Sustained attention in hyperactive children. Journal of Child Psychology \& Psychiatry, 14, 213-220.

Sykes, D. H., Douglas, V. I., Weiss, G., \& Minde, K. K. (1971). Attention in hyperactive children and the effect of methylphenidate (Ritalin). Journal of Child Psychology \& Psychiatry, 12, 129-139.

Wohlberg, G. W., \& Kornetsky, C. (1973). Sustained attention in remitted schizophrenics. Archives of General Psychiatry, 28, 533-537. 
APPENDIX

IMT/DMT Printer Output

Immediate and Delayed Memory Task (Version 1.3)

Donald M. Dougherty, Ph.D.

The University of Texas - Houston Health Science Center

Phone: (713) 500-2625 Fax: (713) 500-2634

Email: Donald.M.Dougherty@uth.tmc.edu

\begin{tabular}{ll} 
Subject Number: 1994 & $\begin{array}{l}\text { Date: } 10 / 04 / 01 \\
\text { Session Start Time: 12:44 PM }\end{array}$ \\
\hline
\end{tabular}

\section{IMMEDIATE MEMORY TASK DATA:}

\begin{tabular}{|c|c|c|c|c|c|}
\hline \multicolumn{4}{|c|}{ Correct Detections } & \multicolumn{2}{|c|}{ Commission Errors } \\
\hline Block & Responses & $\underline{\text { Trials }}$ & Percent & $\underline{\text { Responses }}$ & Percent \\
\hline 1 & 50 & 56 & 89.29 & 3 & 06.12 \\
\hline 2 & 54 & 58 & 93.10 & 9 & 15.79 \\
\hline Totals & 104 & 114 & 91.23 & 12 & 11.32 \\
\hline \multicolumn{4}{|c|}{ Filler Errors } & \multicolumn{2}{|c|}{ Latency Data } \\
\hline$\underline{\text { Block }}$ & $\underline{\text { Responses }}$ & $\underline{\text { Trials }}$ & $\underline{\text { Percent }}$ & Target Stimuli & $\underline{\text { Catch Stimuli }}$ \\
\hline 1 & 2 & 168 & 01.19 & 589.92 & 512.92 \\
\hline 2 & 0 & 158 & 00.00 & 574.15 & 622.07 \\
\hline Totals & 2 & 326 & 00.61 & 581.73 & 594.78 \\
\hline \multicolumn{6}{|c|}{ DELAYED MEMORY TASK DATA: } \\
\hline \multicolumn{4}{|c|}{ Correct Detections } & \multicolumn{2}{|c|}{ Commission Errors } \\
\hline Block & $\underline{\text { Responses }}$ & $\underline{\text { Trials }}$ & Percent & $\underline{\text { Responses }}$ & $\underline{\text { Percent }}$ \\
\hline 1 & 14 & 14 & 100.00 & 3 & 23.08 \\
\hline 2 & 9 & 9 & 100.00 & 2 & 12.50 \\
\hline Totals & 23 & 23 & 100.00 & 5 & 17.24 \\
\hline \multicolumn{4}{|c|}{ Filler Errors } & \multicolumn{2}{|c|}{ Latency Data } \\
\hline$\underline{\text { Block }}$ & Responses & Trials & $\underline{\text { Percent }}$ & Target Stimuli & Catch Stimuli \\
\hline 1 & 0 & 41 & 00.00 & 616.14 & 692.60 \\
\hline 2 & 0 & 43 & 00.00 & 605.36 & 686.41 \\
\hline \multirow[t]{2}{*}{ Totals } & 0 & 84 & 00.00 & 611.92 & 690.12 \\
\hline & \multicolumn{3}{|c|}{ Distracter Errors } & & \\
\hline Block & Responses & Trials & $\underline{\text { Percent }}$ & & \\
\hline 1 & 0 & 205 & 00.00 & & \\
\hline 2 & 1 & 205 & 00.49 & & \\
\hline Totals & 1 & 410 & 00.24 & & \\
\hline
\end{tabular}


APPENDIX (Continued)

\begin{tabular}{|c|c|c|c|c|}
\hline \multicolumn{5}{|c|}{ SIGNAL DETECTION PARAMETERS: } \\
\hline \multicolumn{3}{|l|}{$\begin{array}{l}\text { Discriminability: } \\
d^{\prime} \text { (parametric) }\end{array}$} & diate Memory De & yed Memory \\
\hline \multicolumn{3}{|c|}{$\begin{array}{l}\text { Values can range from } 0 \text { to }>3.0 \text { ( } z \text {-score). Low values } \\
\text { indicate poor discriminability. }\end{array}$} & 2.57 & 3.28 \\
\hline \multicolumn{5}{|c|}{$A^{\prime}$ (nonparametric) } \\
\hline \multicolumn{3}{|c|}{$\begin{array}{l}\text { Values typically range from } 0.5 \text { to } 1.0 \text {. A value equal to } 0.5 \\
\text { indicates chance, and a } 1.0 \text { indicates perfect discrimination. }\end{array}$} & 0.94 & 0.96 \\
\hline \multicolumn{5}{|l|}{ Bias: } \\
\hline \multicolumn{5}{|c|}{ Beta (parametric) } \\
\hline \multicolumn{3}{|c|}{$\begin{array}{l}\text { Values typically range from } 0 \text { to }>3.0 \text {. Lower values indicate } \\
\text { a lax criterion (liberal reporting) and higher values indicate a } \\
\text { strict criterion (conservative reporting). }\end{array}$} & 0.87 & 0.10 \\
\hline \multicolumn{5}{|c|}{$\mathrm{B}^{\prime \prime}{ }_{\mathrm{d}}$ (nonparametric) } \\
\hline \multicolumn{3}{|c|}{$\begin{array}{l}\text { Values range from }-1.0 \text { to }+1.0 \text {. Negative values indicate a } \\
\text { a lax criterion (liberal reporting) and positive values indicate } \\
\text { a strict criterion (conservative reporting). }\end{array}$} & -0.14 & -1.00 \\
\hline \multicolumn{5}{|c|}{ Parameters for this Immediate then Delayed Memory Task session were set as follows: } \\
\hline SESSION: & Number of Blocks $=2$ & Number of Digits $=5$ & Type of Distracto & $=" 12345 "$ \\
\hline PROBABILITY: & Target $=33 \%$ & Catch $=33 \%$ & Filler $=34 \%$ & \\
\hline TEMPORAL: & Stimulus $=500 \mathrm{msec}$ & Blackout $=500 \mathrm{msec}$ & Block $=300 \mathrm{sec}$ & Rest $=30 \mathrm{sec}$ \\
\hline
\end{tabular}

(Manuscript received October 11, 2001; revision accepted for publication May 5, 2002.) 